\title{
Archives in a changing climate: responding to a diversity of environments
}

\author{
Fiorella Foscarini $^{1}$ (D) Viviane Frings-Hessami $^{2}$
}

Published online: 11 October 2019

(c) Springer Nature B.V. 2019

This issue is the second of two special issues of Archival Science dedicated to papers from the Eighth International Conference on the History of Records and Archives (I-CHORA 8), which was held at Monash University in Melbourne, Australia, on 28-30 May 2018. The I-CHORA conference series focuses on the histories of concepts, principles, methods, and practices that have over time characterized the recordkeeping discipline, as we may call it today. According to Barbara Craig, Philip Eppard, and Heather MacNeil, the organizers of the first I-CHORA which took place in Toronto in 2003,

Many archivists [are] acutely aware that they lack their own history as a profession, particularly of the functions they profess as appraisers, selectors, preservers, and enablers of use. Like the cobbler's children who are poor in the very products the cobbler purveys, archivists are discovering, or re-discovering that their work, their institutions, and their materials have a rich history that is neither obvious, simple, transparent, nor beyond debate (Craig et al. 2005, p 3).

I-CHORA was conceived as a vehicle for an interdisciplinary dialogue around the different sociocultural, political, and technological contexts in which records have been created, used, and preserved over the centuries and the roles they have played in the lives of organizations, communities, and individuals.

The success of this initiative can be measured not only through the number of I-CHORA conferences hosted in different parts of the world since 2003 (FringsHessami and Foscarini 2019) but also through the numerous scholarly publications that have arisen from each of these conferences. The following overview is not

Fiorella Foscarini

fiorella.foscarini@utoronto.ca

Viviane Frings-Hessami

viviane.hessami@monash.edu

1 Faculty of Information, University of Toronto, Toronto, Canada

2 Faculty of Information Technology, Centre for Social and Organisational Informatics, Monash University, P.O. Box 197, Caulfield East, VIC 3145, Australia 
meant to be exhaustive, as several I-CHORA papers have been disseminated outside of dedicated publications.

Selected papers presented at the first I-CHORA were published in a special issue of Archivaria (Craig et al. 2005); I-CHORA 2 papers were included in two themed issues of Archival Science (Anderson et al. 2006); a selection of papers from I-CHORA 3 was published in Libraries and the Cultural Record (Craig 2009); I-CHORA 4 papers appeared in Archival Science (Sassoon and Burrows 2009); the Journal of the Society of Archivists published papers presented at I-CHORA 5 (Williams and Procter 2011); papers from I-CHORA 6 appeared in Information and Culture (Riordan 2013); and selected papers presented at I-CHORA 7 were published in book format (Foscarini et al. 2016).

The theme of I-CHORA 8, "Archives in a Changing Climate" (http://ichora.org/), inspired submissions related, inter alia, to issues of identity and memory, evolving professional discourses, and records displacement and return. What the three articles selected for this second special issue have in common is that they all explore the complexities of diverse archival environments and trace a historical trajectory until the present days. Jesse Johnston, Ricardo Punzalan, and David Wallace consider the National Archives and Records Administration's (NARA) policies and practices concerning presidential emails in the US. Kirsten Wright discusses ways to deal with culturally insensitive language used in the archival descriptions of historical records relating to child welfare in Australia. Finally, James Lowry proposes a research agenda for displaced colonial archives. All three articles reflect on access issues and their intricacies. Johnston et al. are concerned with ensuring that US presidential emails will be preserved and accessible in the future; Wright focuses on improving archival description to facilitate access to records for Care Leavers; and Lowry deals with ensuring access to archives which have been displaced from their contexts of creation for communities that have been deprived of their heritage.

Since both Wright's and Lowry's articles insist on the key role played by language in processes of "decolonization", or more broadly, "humanization", of the archives, we deemed it appropriate to conclude this special issue with an article written by Alicia Chilcott. Although it was not presented at I-CHORA 8, Chilcott's examination of the problem of racially offensive language in UK public archives may be seen as in dialogue with Wright's contribution on descriptive practices, but also as a first step in implementing Lowry's research agenda.

Starting with the first I-CHORA paper included in this special issue, Johnston et al.'s discussion of presidential emails is more than an overview of how US legislation has attempted to regulate the use of emails as government records in the past three decades. The article offers a well-documented and thoughtful picture of a controversial situation which goes beyond the "email problem", and has several political and ethical implications. The authors' investigation is guided by the question: Is the archival tenet of accountability meaningful in the face of the changing technological and political challenges presented by emails as records? By using emails as an example, they question the traditional role of archivists as "agents of accountability", and argue that the profession must reframe archival accountability by acknowledging the power imbalances existing within organizations and among different professional groups. From the "print and file" approach of the 1980s to the "capstone 
project" that was launched in 2013 , the US federal email policy has progressively reduced the responsibility of both archivists and email creators over the selection of the emails to be retained, under the general assumption that those emanating from senior officials would be of highest value. More generally, Johnston et al. argue that current US regulations do not provide for an active role of recordkeepers early in the record life cycle. Therefore, the profession should reconsider its positioning around accountability, and be open to scaling back expectations.

Wright's article discusses the use of language in record descriptions available via the Find \& Connect Web Resource (https://www.findandconnect.gov.au/), which was developed in Australia to support adults who spent time in care as a child (a.k.a., Care Leavers) by providing access to information relating to the history of child welfare in Australia. The web resource does not host records, but provides information about records held by a wide variety of institutions. The item-level descriptions in Find \& Connect attempt to make both the perspectives of the institutions and those of the Care Leavers available side by side to provide meaningful contexts to the institutions and the records. The titles identifying the digitised documents and photographs one may find through Find \& Connect are the same as they were in the original sources. The language used in those descriptions may sometimes be perceived as offensive. Recognizing that the uncritical reproduction of historical language in the description of archival resources may distress and alienate potential users, the Find \& Connect team decided to adopt a policy by which the original titles are maintained in a field called "archival reference", thus ensuring that the documents can still be located in the repositories and providing evidence of the language used at the time, but also making it clear that these were titles included in the original sources and not titles attributed by the Find \& Connect team. Like some of the articles included in the first special issue dedicated to I-CHORA 8 (O'Neill 2019; Frings-Hessami 2019; McKemmish et al. 2019), Wright's article elaborates on the concept of rights in records developed by Gilliland and McKemmish (2015) and the need to ensure that descriptive practices, access and disclosure processes "do not expose or exploit those who are vulnerable to suppression, appropriation, violence, discrimination, or other oppressive or traumatizing acts, or re-traumatize them" (p. 120).

In the last I-CHORA paper of this special issue, Lowry develops his opening keynote address, enriched by discussions with conference participants, into a research agenda for displaced archives. Defining "displaced archives" as any records that have been removed from the context of their creation and whose ownership is disputed, Lowry stresses the need for more research in order to contextualize the phenomenon of displaced archives. Three elements would be especially needed: the compilation of a multilingual bibliography on the topic, more information about the extant cases, and single and comparative cases studies and investigations into the history of the phenomenon, so as to contribute to a better understanding of the contexts of displaced archives. Moreover, he suggests that applying a continuum perspective to the study of displaced archives could radically reshape how archival displacement is conceived and that further research is needed in this area. The application of post-custodial thinking to displaced archives could thoroughly change the displacement discourse and lead to a different understanding of displacement 
independent of the location of the archives, but complicated by the introduction of the notions of place and data sovereignty in the digital environment. Lowry also suggests looking at the work that has been done in recent years on the materiality of archives, and among other theoretical possibilities, at the concept of rights in records, which could present the notion of archival displacement in a new light and contribute to new critical perspectives. Finally, noting that the writing on displaced archives has been dominated by the Global North, Lowry argues that future work on this issue should offer more opportunities to express themselves to those most affected by displaced archives, who are mostly located in the Global South.

Concerned about the harm that records containing racist language can cause to the subjects and the users of such records, and more generally, about the apparent inability of archival institutions to transform their practices radically and move away from their colonial roots, Chilcott reviews current approaches to the description of racially offensive material in UK public archives and suggests various possible ways to improve existing practice. Following Australian and North American examples of culturally sensitive representation strategies and protocols, Chilcott provides UK archivists-but her proposal could be extended to most countries-with practical, scalable recommendations for the description of records containing offensive racial terms, as a starting point for further discussion.

\section{References}

Anderson K, Ketelaar E, Yakel E (2006) Preface. Arch Sci 6(3-4):265

Craig BL (2009) Introduction. Libr Cult Rec 44(1):1-8

Craig BL, Eppard PB, MacNeil H (2005) Exploring perspectives and themes for histories of records and archives: the first international conference on the history of records and archives (I-CHORA). Archivaria 60:1-10

Foscarini F, MacNeil H, Mak B, Oliver G (eds) (2016) Engaging with records and archives: histories and theories. Facet, London

Frings-Hessami V (2019) Khmer rouge archives: appropriation, reconstruction, neo-colonial exploitation and their implications for the reuse of the records. Arc Sci 19(3):255-279

Frings-Hessami V, Foscarini F (2019) Archives in a changing climate: proposing new "solutions" for a new era. Arch Sci 19(3):209-213

Gilliland AJ, McKemmish S (2015) Rights in records as a platform for participatory archiving. In: Cox RJ, Langmead A, Mattern E (eds) Archival education and research: selected papers from the 2014 AERI conference. https://escholarship.org/uc/item/5g3135n6. Accessed 16 June 2019

McKemmish S, Chandler T, Faulkhead S (2019) Imagine: a living archive of people and place "somewhere beyond custody". Arch Sci 19(3):281-301

O'Neill C (2019) The shifting significance of child endowment records at the National Archives of Australia. Arch Sci 19(3):235-253

Riordan M (2013) The king's library of manuscripts: the state paper office as archive and library. Inf Cult A J History 48(2):181-193

Sassoon J, Burrows T (2009) Introduction: minority reports: indigenous and community voices in archives. Arch Sci 9:1-2

Williams C, Procter M (2011) Editorial: archives, records and technology: their interdependence over time. J Soc Arch 32(1):1-3

Publisher's Note Springer Nature remains neutral with regard to jurisdictional claims in published maps and institutional affiliations. 
Fiorella Foscarini is Associate Professor in the Faculty of Information at the University of Toronto (CA). She holds a Ph.D. in Archival Studies from the University of British Columbia, Vancouver (CA), and also taught with the University of Amsterdam (NL). Before joining academia, she worked as an archivist and a records manager for the European Central Bank in Frankfurt am Main (DE) and the Province of Bologna (IT). She was a member of the Program and Organising Committees for the latest two editions of the International Conference on the History of Records and Archives (I-CHORA 7 and I-CHORA 8), which took place in Amsterdam (NL) in 2015 and Melbourne (AU) in 2018, respectively. She currently serves as General Editor of Archivaria.

Viviane Frings-Hessami is a Lecturer in the Centre for Organisational and Social Informatics at Monash University, Melbourne, Australia, where she teaches the Archives and Recordkeeping units. She holds a Ph.D. in Political Science and a Graduate Diploma in Information and Knowledge Management from Monash University. Her current research is investigating the impact of cultural factors on digital continuity. She was part of the organizing committee for the International Conference on the History of Records and Archives (I-CHORA 8), which was held at Monash University in May 2018. She is also General Editor of Archives \& Manuscripts, the journal of the Australian Society of Archivists. 